\title{
Immunogenicity of Streptococcus pneumoniae 74 kDa Surface Protein in Rabbit Model
}

\author{
Zeenat Jahan, Iztiba Mallik Deeba, Shahina Akter, Tasmina Rahman, Ashikun Nabi, Mahmuda Yasmin, Jamalun \\ Nessa and Chowdhury Rafiqul Ahsan* \\ Department of Microbiology, University of Dhaka, Dhaka 1000, Bangladesh
}

\begin{abstract}
Immunogenicity of a pneumococcal $74 \mathrm{kDa}$ surface protein in the rabbit model was investigated in this study. For this, Streptococcus pneumoniae serotype $7 \mathrm{~F}$ was collected and water extraction procedure was applied for the preparation of surface materials, which was used for further isolation of the $74 \mathrm{kDa}$ surface protein. Rabbits were immunized with the sonicated nitrocellulose membrane containing the $74 \mathrm{kDa}$ surface protein and the control group of rabbits was injected with same concentration of sonicated nitrocellulose membrane only. The antibody response against the $74 \mathrm{kDa}$ surface protein was evaluated by both ELISA and immunoblot assay. Sera collected from the $\mathbf{7 4} \mathrm{kDa}$ surface protein immunized rabbits were examined and the high titre $(1: 1600)$ ELISA values $\left(\mathrm{OD}_{490}\right)$ indicated the production of adequate amounts of anti-74 $\mathrm{kDa}$ antibodies in the rabbits. In the immunoblot analysis, a single antigenic band was obtained on the nitrocellulose membrane treated with sera obtained from rabbits immunized with the $74 \mathrm{kDa}$ surface protein. The high titre antibody production in the rabbits indicates the immunogenicity of the $74 \mathrm{kDa}$ surface protein in rabbit model.
\end{abstract}

Keywords: Streptococcus pneumoniae, surface protein, immunogenicity

\section{Introduction}

Streptococcus pneumoniae, also known as pneumococcus, is one of the leading causes of childhood pneumonia and meningitis. This organism accounts for 20 to $40 \%$ of the estimated annual global burden of 2.7 million childhood deaths from pneumonia in developing countries ${ }^{1-2}$ and the second leading cause of meningitis in children in Bangladesh ${ }^{3-4}$. The polysaccharide capsule of $S$. pneumoniae has been considered the primary virulence factor because non-encapsulated bacteria are essentially harmless compared with the same encapsulated strain. Recent studies, however, have suggested that certain pneumococcal proteins on the surface of $S$. pneumoniae may also be important virulence factors in the pathogenesis of infection and disease, and potentially for the development of new vaccines $^{5-6}$. These proteins enable $S$. pneumoniae to evade host defenses and cause invasive disease by concealing and protecting the bacterial surface from host immune defenses and interacting with host tissues to facilitate bacterial colonization; adherence and ultimately pulmonary and extra-pulmonary dissemination, bacteraemia, and systemic disease ${ }^{7}$.

The laboratory diagnosis of invasive pneumococcal disease (IPD) continues to rely on culture-based methods that have been used for many decades. The most significant recent developments have occurred with antigen detection assays, whereas the role of nucleic acid amplification tests has yet to be fully clarified. Despite developments in laboratory diagnostics, a microbiological diagnosis is still not made in most cases of IPD, particularly for pneumococcal pneumonia ${ }^{8}$. The limitations of existing diagnostic tests impact the ability to obtain accurate IPD burden data and to assess the effectiveness of control measures, such as vaccination, in addition to the ability to diagnose IPD in individual patients. Therefore, there is a need for improved diagnostic tests for pneumococcal disease - especially tests that are suitable for use in under resourced countries ${ }^{8}$. In recent years, a $74 \mathrm{kDa}$ unique pneumococcal surface protein was identified in the Department of Microbiology, University of Dhaka (unpublished data). This protein was found to be located on the surface of different predominant serotypes of $S$. pneumoniae. In the present study, we have demonstrated the immunogenicity of the $74 \mathrm{kDa}$ pneumococcal surface protein in rabbit model and investigated the titre of the antibodies so that a high titre anti- $74 \mathrm{kDa}$ antibody may be used for the rapid diagnosis of this bacterium.

\section{Materials and Methods \\ Bacterial strain}

The experiments of this study were carried out in the Department of Microbiology, University of Dhaka, Bangladesh. The S. pneumoniae serotype 7F used in this study was obtained from the stock culture of the Department of Microbiology, Dhaka Shishu (Children) Hospital. Originally the S. pneumoniae strain was collected from the out-andin patients of Dhaka Shishu Hospital and was serotyped by capsular swelling procedure (Quellung reaction) with type specific anti pneumococcal pool, type or group, and factor sera. However, identity of this organism was reconfirmed by the Gram staining, optochin susceptibility and bile solubility tests. 


\section{Preparation of surface materials}

Water extraction procedure was applied to prepare the surface materials from the $S$. pneumoniae organisms following the method described by Oaks et al. ${ }^{9}$. The organism was grown in Brain heart infusion (BHI) broth supplemented with $10 \%$ foetal bovine serum (FBS) at $37^{\circ} \mathrm{C}$ for 24 hours on a shaker. The whole culture medium was harvested by centrifugation (10,000x g for $20 \mathrm{~min}$ ) and the supernatant was discarded. The pellet was washed three times in normal saline, re-suspended in 20 volumes of distilled water and shaken (100 oscillations per min) for 6 hours at room temperature. The suspension was centrifuged at 10,000x g for 20 min and supernatant containing the surface materials, was filtered through a $0.45 \mathrm{im}$ millipore membrane filter and stored at $-20^{\circ} \mathrm{C}$ in aliquots until used.

\section{Isolation of the $74 \mathrm{kDa}$ surface protein}

Protein profile of the $S$. pneumoniae surface material was analyzed by sodium dodecyl sulphate-polyacrylamide gel electrophoresis (SDS-PAGE) $^{10}$ on a $10 \%$ separating gel. Pre-stained molecular weight markers (BioRad, USA) were run in one of the wells. Proteins in gel were transferred to a nitrocellulose membrane ${ }^{11}$ and detected using amido black staining. The $74 \mathrm{kDa}$ protein band, detected after comparing with the molecular weight markers, was cut out carefully and sonicated in phosphate buffered saline (PBS) until the membrane reduced to a fine powder enough to pass through a $22 \mathrm{G}$ hypodermic needle ${ }^{12}$.

Immunization of rabbits with the isolated $74 \mathrm{kDa}$ surface protein A total of five New Zealand white female rabbits (1.5-2.0 kg body weight) were used for this study, which were housed with adequate food and fresh water supply. All experiments using animals were undertaken following ethical issues set by the Faculty of Biological Sciences, University of Dhaka. Three of the rabbits were immunized with the isolated $74 \mathrm{kDa}$ surface protein at days 0,28 and 42 via intramuscular route. Remaining two rabbits, which were injected with the same concentration of the sonicated nitrocellulose membrane only, served as negative controls. Sera (approximately $3 \mathrm{ml}$ ) collected from the rabbits before immunizations, served as non-immunized control sera. During the whole immunization period, blood was collected from the marginal ear veins at one week intervals to check the immune response of the $74 \mathrm{kDa}$ surface protein. Final blood was collected by cardiac puncture seven days after the last booster dose and all sera were aseptically separated from blood samples by centrifugation at 3,000 rpm for $10 \mathrm{~min}$.

\section{Absorption of the sera}

Sera collected from the rabbits immunized with the $74 \mathrm{kDa}$ surface protein or the sonicated nitrocellulose membrane only, were all separately mixed with the sonicated nitrocellulose membrane and kept overnight at $4^{\circ} \mathrm{C}$ for complete binding of the antibody with the nitrocellulose membrane. The suspension was then centrifuged at 3,000 rpm for 10 min so that the nitrocelluloseantibody complexes were deposited as pellet and the supernatants were stored at $-20^{\circ} \mathrm{C}$ for further analysis.
Immunogenicity of the $74 \mathrm{kDa}$ surface protein

(i) Enzyme-linked immunosorbent assay (ELISA)

Antibody titres of the rabbit anti-74 kDa surface protein were determined by ELISA using a 96 -well plate ${ }^{13}$. An aliquot of surface materials prepared earlier was diluted in coating buffer to a final concentration of $5 \mu \mathrm{g}$ per $100 \mu \mathrm{l}$ and added to each well. After overnight incubation at $4{ }^{\circ} \mathrm{C}$, the wells were blocked with $1 \%$ bovine serum albumin (BSA) and reacted with diluted rabbit anti$74 \mathrm{kDa}$ surface protein sera (1:50, 1:100, 1:200, 1:400, 1:800, 1:1600 and 1:3200). After vigorous washing, secondary antibody, horse radish peroxidase (HRP) conjugated goat anti-rabbit IgG (whole molecule, Sigma, USA) diluted to 1:10,000, was added into the wells. Substrate was added to the wells after vigorous washing and intensity of the color was read at $490 \mathrm{~nm}$ by an ELISA reader (Bio Rad, USA). Each experiment was done in triplicate.

(ii) Immunoblot analysis

Surface materials were subjected to SDS-PAGE analysis as described above $\mathrm{e}^{10}$, and the proteins in gel were transferred to a nitrocellulose membrane ${ }^{11}$. After blocking the membrane with 3\% skimmed milk in PBS, the membrane was incubated with rabbit sera (both $74 \mathrm{kDa}$ surface protein and nitrocellulose membrane immunized) at a dilution of 1:100 in PBS. Following washing, the membrane was incubated with HRP conjugated goat anti-rabbit IgG. The membrane was dipped in the substrate solution until antigenic band(s) had appeared and the reaction was stopped by washing the membrane in water.

\section{Results and Discussion}

In this study, the objective was to observe the long term systemic immunogenicity of the pneumococcal $74 \mathrm{kDa}$ surface protein in the rabbit model. For this, surface proteins of the $S$. pneumoniae were extracted by the water extraction procedure and later the 74 $\mathrm{kDa}$ surface protein was isolated by the SDS-PAGE and immunoblot method ${ }^{12}$.

The water extraction procedure, applied for the isolation of the surface material from the bacterial strains, is a simple low ionic strength extraction by the use of distilled water, has been used previously to release surface protein components from other sources $^{9}$. As such extraction procedure does not contain any chemical treatment or drastic conditions, there is less possibility of altered immunological specificity of the product and the proteins may remain in their native non-dissociated conformation, which has been confirmed by the single antigenic band obtained in the immunoblot experiment.

The antibody response against the $74 \mathrm{kDa}$ surface protein was evaluated by both ELISA and immunoblot analysis. Sera collected from the $74 \mathrm{kDa}$ surface protein immunized rabbits for seven weeks were examined and the high titre (1:1600) ELISA values $\left(\mathrm{OD}_{490}\right)$ indicated the production of adequate amounts of anti-74 kDa antibodies in the rabbits (Figure 1). However, the negative control sera collected from rabbits on day 0 before immunization with the $74 \mathrm{kDa}$ surface protein or rabbits injected with sonicated membrane only, showed no antibodies against the $74 \mathrm{kDa}$ surface protein, as demonstrated by the low titre $\mathrm{OD}_{490}$ values. Using ELISA values for 1:50 dilution on different 
days (7, 14, 21, 28 and 35), a plot of OD $_{490}$ versus time (days) was drawn (Figure 2). The graph showed a significant increase in pneumococcal anti-74 kDa antibody with time. Production of antibody increased almost exponentially up to day 21 and after that, it almost maintained the same level until day 50. Similar results were also obtained from other dilutions of 1:100, 1: 200, 1:400 and 1: 800 (data not shown).

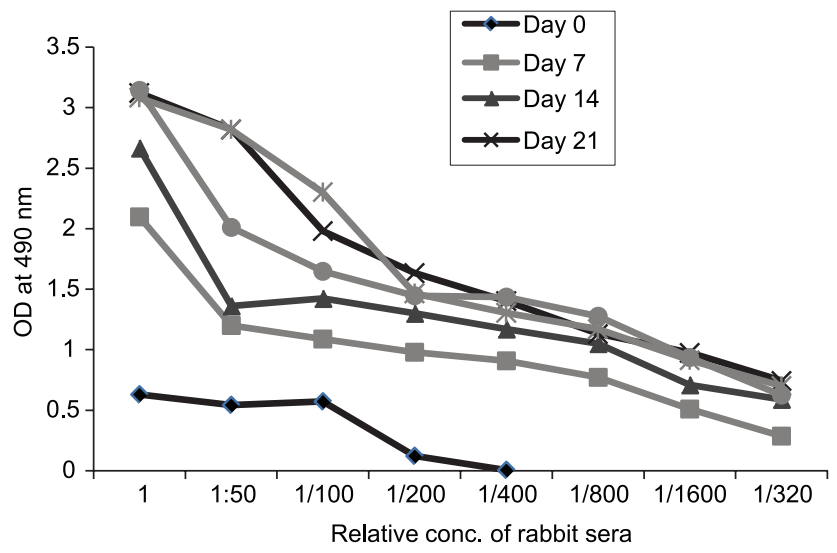

Figure 1. The antibody response against the $74 \mathrm{kDa}$ surface protein was evaluated by ELISA method. Sera collected from the $74 \mathrm{kDa}$ surface protein immunized rabbits for seven weeks were examined and the high titre $(1: 1600)$ ELISA values $\left(O D_{490}\right)$ indicated the production of adequate amounts of anti-74 $\mathrm{kDa}$ antibodies in the rabbits. Values shown are the mean of three experiments.
In the immunoblot analysis, a prominent antigenic band was obtained on the nitrocellulose membrane treated with sera obtained from rabbits immunized with the $74 \mathrm{kDa}$ surface protein (Figure 3). Molecular weight of the antigenic band was found to be $74 \mathrm{kDa}$, as confirmed by comparing with the molecular weight standards, indicating the immunogenicity of the $74 \mathrm{kDa}$ pneumococcal surface protein in rabbit model.

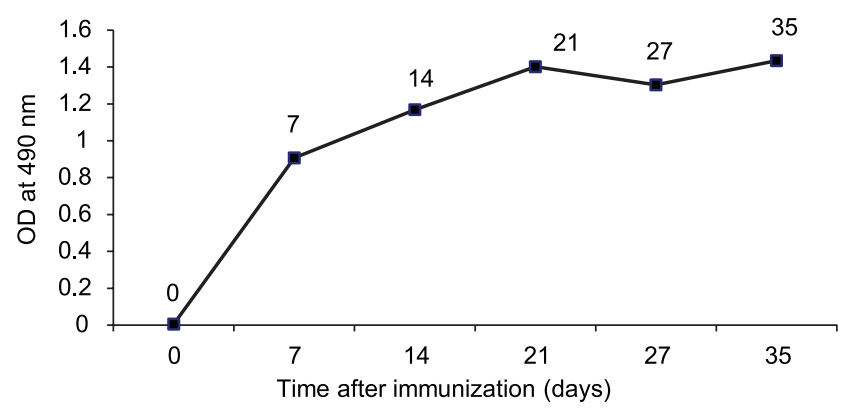

Figure 2. Kinetics of anti-74 $k D a$ surface protein antibody response in rabbits. Using ELISA values for 1:50 dilution on different days (7, 14, 21, 28 and 35), a plot of $O D_{490}$ versus time (days) was drawn. A significant increase in pneumococcal anti-74 kDa antibody with time was found. Production of antibody increased almost exponentially up to day 21 and after that, it almost maintained the same level until day 35. Values shown are the mean of three experiments.

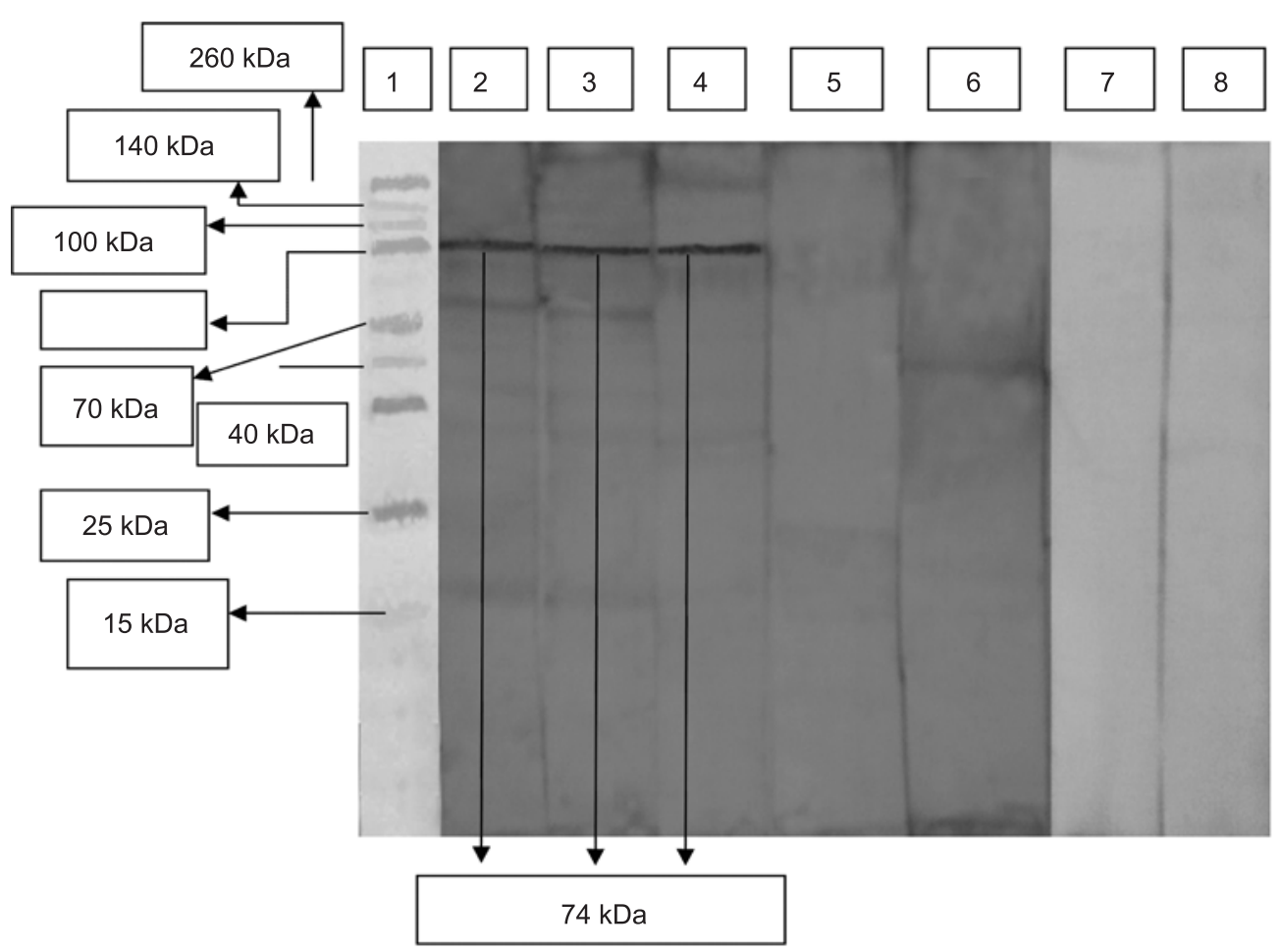

Figure 3. Immunoblot analysis of the antibody reactivity in nitrocellulose adsorbed sera from immunized rabbits. A prominent antigenic band was obtained on the nitrocellulose membrane treated with sera obtained from rabbits immunized with the 74 kDa 
The pneumococcal $74 \mathrm{kDa}$ surface protein has been found to be a unique surface protein present in many of the predominant serotypes of the $S$. pneumoniae (unpublished data). The high titre antibody production in the rabbits indicate the immunogenicity of the $74 \mathrm{kDa}$ surface protein in rabbit model and the sera of rabbits may be a good source of antibodies to be used for immunological diagnosis of the $S$. pneumoniae irrespective of the serotype distribution. However, further characterization of the $74 \mathrm{kDa}$ surface protein is necessary to confirm other functions of this protein.

\section{References}

1. Mulholland K.1999. Magnitude of the problem of childhood pneumonia. Lancet. 354: 590-592.2.

2. Obaro SK, Monteil MA and Henderson DC. 1996. The pneumococcal problem. Br Med J. 312: 1521-1525.

3. Rahman, MF, Huq F and Sack DA. 1990. Acute lower respiratory infection in hospitalized patients with diarrhea in Dhaka, Bangladesh. Rev Infect Dis. 12: S889-S906.

4. Saha SK, Rikitomi N, Ruhulamin M, Watanabe K, Ahmed K, Biswas D, Hanif M, Khan WH, Islam M, Matsumoto K and Nagatake T. 1997. The increasing burden of disease in Bangladeshi children due to Haemophilus influenza type meningitis. Ann Trop Paediatr. 17: 5-8.

5. Briles DE, Hollingshead SK, Swiatlo E, Brooks-Walter A, Szalai A, Virolainen A, McDaniel LS, Benton KA, White P, Prellner K, Hermansson A, Aerts PC, Van Dijk H and Crain MJ. 1997. PspA and
PspC: Their potential for use as pneumococcal vaccines. Microb Drug Resist. 3: 401-408.

6. Ferreira DM, Darrieux M, Silva DA, Leite LC, Ferreira JM Jr, Ho PL, Miyaji EN and Oliveira ML. 2009. Characterization of protective mucosal and systemic immune responses elicited by pneumococcal surface protein PspA and PspC nasal vaccines against a respiratory pneumococcal challenge in mice. Clin Vaccine Immunol. 16: 636-645.

7. Jedrzejas MJ. 2001. Pneumococcal virulence factors: Structure and function. Microbiol Mol Biol Rev. 65: 187-207.

8. Werno AM and Murdoch DR. 2008. Medical microbiology: Laboratory diagnosis of invasive pneumococcal disease. Clin Infect Dis. 46: 926-932.

9. Oaks EV, Hale TL and Formal SB. 1986. Serum immune response to Shigella protein antigens, rhesus monkeys and human infected with Shigella species. J Infect Immun. 53: 57-63.

10. Laemmli UK, Beguin F and Gujer-Kellenberger G. 1970. A factor preventing the major head protein of bacteriophage $\mathrm{T} 4$ from random aggregation. J Mol Biol. 47: 69-85.

11. Towbin H, Staehelin T and Gordon J.1979. Electrophoretic transfer of proteins from polyacrylamide gels to nitrocellulose sheets: procedure and some applications. Proc Natl Acad Sci USA. 76: 4350-4354.

12. Diano M, Le Bivic A and Hirn M. 1998. Raising polyclonal antibodies using nitrocellulose-bound antigen. Methods Mol Biol. 80: 5-13.

13. Sack DA, Neogi PK and Alam MK. 1980. Immunobead enzymelinked immunosorbent assay for quantitating immunoglobulin A in human secretions and serum. Infect Immun. 29: 281-283. 